\title{
sciendo
}

DOI 10.2478/sbe-2020-0015

SBE no. 15(1) 2020

\section{PERFORMANCE-RISK NEXUS OF GLOBAL LOW-RATED ETFS DURING THE QE-TAPERING PERIOD}

\author{
PANAGIOTIS ANASTASIADIS \\ University of Thessaly, Volos, Greece \\ EFTHIMIOS KATSAROS \\ University of Thessaly, Volos, Greece
}

ANASTASIOS-TAXIARCHIS KOUTSIOUKIS

University of Thessaly, Volos, Greece

ATHANASIOS PANDAZIS

University of Thessaly, Volos, Greece

\begin{abstract}
:
This study investigates the performance of $50 \mathrm{global}$, one star (based on Morningstar rankings), ETFs during the US QE-tapering period starting in October 2014 up to September 2018, using the S\&P500 as the market index. The methodology employed is based on the CAPM model. We adopt the Jensen's Alpha, Beta, a / b, Sharpe and Treynor ratios measures in order to examine whether those ETFs have achieved abnormal returns. We conclude that managers of most ETFs do not exhibit selectivity skills and only six of these ETFs achieve higher returns than the market by showing bullish behavior. At the same time, most ETFs have positive Sharpe and Treynor ratios due to high expected returns during the period under scrutiny.
\end{abstract}

Key words: ETF, CAPM, Selectivity skills, Sharpe, Treynor, QE-tapering

\section{Introduction}

This paper conducts the performance evaluation of 50 global ETFs and we examine whether they outperform the market, which is represented by the S\&P500 index. The reason why we selected exchange-traded funds (ETFs) is because it is a modern and sophisticated type of mutual funds whose key feature is that it can be traded on a daily basis but also preserving the characteristics of mutual funds and stocks. This renders ETFs a special financial product of great academic interest, which is more pronounced during turbulent eras. ETF is a marketable security tracking an equity index, a commodity, bonds, or a basket of assets. First, ETFs are traded throughout the day and not just at the 
close of the trading day. Secondly, ETFs are more transparent. Investors can see daily the stocks or other products that make up their shares. The index prices on which they rely are public and known; on the contrary, mutual funds do not often disclose the shares they have in their portfolio. The largest ETFs exhibit higher daily volume on average and less cost in comparison to mutual fund shares. What basically differentiates ETFs from mutual funds is their higher tax effectiveness that makes them more attractive to investors and attaches a more sophisticated character to them (Kostovetsky, 2003).

As a study period, we choose the period starting from October 2014 and enduring up to the present. This period represents the time that the Federal Reserve System ended quantitative easing (QE) that represented extra easing monetary action taking (Fawley and Neely, 2013) and has triggered a proliferating bulk of academic interest. QE means largescale asset purchases for providing a spur to financial and macroeconomic variables. It is employed in highly distressed periods when interest rates have reached the zero lower bound (ZLB) so conventional monetary policy renders inefficient (Joyce et al., 2012). QE has had medium impacts on stock indices and the real economy, thereby GDP and inflation became somewhat higher. After the end of QE an increasing number of empirical papers have investigated QE-tapering and the normalization of monetary policies during higher interest rates periods (Aizenman et al., 2014; Chari et al., 2017). Regarding QEtapering, according to Meinusch and Tillmann (2015), it describes the process of sweeping up the extra liquidity injected in financial markets and the real economy by the balance sheet enlargement of the Federal Reserve during QE. It should be noted that QE-tapering was launched in May 2014 sfter the Maturity Extension Program (Foley-Fisher et al., 2016). Specifically, the FED gradually reduced the activities used to improve the conditions for economic growth since it was no longer needed.

Our purpose is to investigate how the 50, one-star based on Morningstar categorization, global ETFs performed after the "regularity" that the US signaled with the end of QE. We aim to draw conclusions on the existence or not of selectivity skills of the fund managers (Jensen's, 1968), on the investing behavior they chose (bullish or bearish) and on the returns of the ETFs in relation to the risk they bear and the systematic risk of the market index to which they are linked. We aim to provide a roadmap to the scientific community, policy makers, investors as well as anyone interested, an innovative perspective on the distinct global financial instrument of ETFs via a framework of analysis based on Morningstar's (one of the most credible and influential investment research and investment management firms globally) classification. The main reason we selected onestar ETFs is that they represent extreme cases of investment assets. Thereby, a crystalclear representation of reactions of lower-rated sophisticated financial instruments during out of the ordinary monetary conditions can be offered.

The remainder of this paper is structured as follows: Section 2 provides the relevant academic work in the form of a literature review. Section 3 presents the data employed and the methodology adopted. Section 4 lays out the econometric results and assessments and analyzes the economic implications. Finally, Section 5 concludes. 


\section{Literature Review}

ETFs, the central subject of our study, are a modern and innovative form of mutual fund that can be traded daily, just like a common stock. According to Poterba and Shoven (2002), they originally appeared in 1993 and by 2001 they already held $2.4 \%$ of the total global equity fund. The authors also argue that ETFs attract the interest of researchers as innovative financial products because they are precursors to innovation and development of the mutual fund market in the future.

This study is based on the Capital Asset Pricing Model (CAPM) which is a spiritual realization of William Sharpe $(1964,1994)$ and John Lintner (1965) based on Markowitz (1959) work on portfolio management. CAPM has been an established model of valuation of capital cost, portfolio and credit performance, for about 50 years, revealing the linkage of the excess returns of each asset under scrutiny with the market returns and the systemic market risk (Beta coefficient) to which it relates. Based on CAPM, the selectivity skills of managers can be traced when mutual funds are investigated.

Fama and French (2004) support the CAPM's ability to adequately relate the expected performance of an investment component to the Beta factor, ie the systemic market risk and its aggressiveness in the process of generating returns. This is not adequately supported by empirical CAPM implementation surveys due to other factors that they do not take into account and because of the simplistic assumptions required to implement it.

We also make use of the Sharpe (Sharpe, 1966) indicator that was invented by William Sharpe and is a well-established ratio in the academic world, measuring the excess returns of securities or portfolios in relation to the risk-free interest rate when the return is adjusted to the risk due to the volatility of the underlying asset. This allows for comparisons that take into consideration the overall risk of the investment items. However, according to Scholz (2007), there have been several critics of this indicator in terms of credibility of its efficacy owing to it being based on statistically calculated data containing a level of error. This has led to the creation of customized indicators based on the original Sharpe index, which attempt to improve its credibility. Israelsen (2004) by modifying the denominator, argues that the Sharpe ratio but also the information ratio offer correct rankings during times of negative excess returns. Gregoriou and Gueyie (2003) employ a modified Sharpe ratio in order to provide a superior tool for correctly measuring riskadjusted performance. They rank 30 funds of hedge funds according to the Sharpe and modified Sharpe ratio. They document that the modified Sharpe is lower and more accurate during the examination of non-normal returns.

Moreover, our study is based on the Treynor index (Treynor, 1966), constructed by Jack Treynor in a mentality similar to the Sharpe index but based only on the systematic risk of the market to which the underlying item is related by the Beta coefficient of the CAPM model. Jobson and Korkie (1981) develop significance tests of portfolio performance by employing the Sharpe and Treynor measures. They propose multivariate performance comparison measures which have a basis on these traditional measures in terms of comparison of the performance of alternative portfolios. Hubner (2005) extends the Treynor performance ratio for a single index to the case of multiple indexes and calls 
this new measure as the Generalized Treynor Ratio. The latter is defined as the abnormal return of a portfolio per unit of premium-weighted average systematic risk, normalized by the premium-weighted average systematic risk of the benchmark. Evidence argues in favor of portfolio rankings produced with this measure exhibiting higher precision and stability in comparison to the ones provided by Jensen's alpha and the Information Ratio. According to Hodges et al. (2003), Treynor indicates the performance of a security or portfolio for each systemic risk unit of a market to which it relates. Therefore, it is not an independent indicator of the item that it examines, but always relevant to the market in which it is applied and correspondingly to the Sharpe index, allowing comparisons between different items within the same market.

Pilotte and Sterbenz (2006) perform a comparison between the Sharpe and the Treynor indexes. The latter is found to be more suitable when estimating the adding of an investment item to a diversified portfolio. On the other hand the Sharpe index is deemed to be more appropriate during assessment of an investment product by the investor that prefers differentiation.

Thanou (2008) analyzed the efficiency of 17 Greek mutual funds during the years 1997-2005. By employing the CAPM model and using the Sharpe and Treynor ratios, it was concluded that the majority of the mutual funds followed the market path, achieving a satisfactory differentiation. In their research, Papadamou and Siriopoulos (2004) looked into short-term returns of mutual funds that invest in European equities and maintain their managers for more than three years. They noted that there was a low performance compared to the market index (Eurostoxx). Mutual funds that earned good returns over a five-month review period continued to perform high in the remaining four months. Mansor and Bhatti (2011) assess overall monthly performances of 128 Islamic mutual funds (IMFs) during the January 1990 - April 2009 period. The measures adopted are the Sharpe, Treynor and Jensen based on extended version of CAPM model. The funds under scrutiny are Malaysian and it is found that they are able to outperform the market. It is also revealed that there are significantly positive stock selectivity capabilities as well as market timing abilities in Malaysia concerning IMFs fund managers. On the other hand, inferior performance in market timing ability is detected in relation to their conventional counterparts.

Swinkels and Rzezniczak (2009) empirically estimate the investment performance of mutual fund managers that operate in the Polish market. The data cover the period 20002007 in order to look into the manager's selectivity and market timing skills. Three investment mutual fund investment categories are investigated: equity, balanced, and bond mutual funds. There is evidence of robustness of findings with respect to the model choice. Insignificant selectivity skills of the mutual fund managers are detected, whereas no bond or equity market timing skills are traced in the sample. Romacho and Cortez (2006) investigate market timing and investment performance of Portuguese based mutual funds that invest in local, European and International stocks. Results reveal that managers do not exhibit selectivity and timing abilities, and there even is some proof of negative timing. Moreover fund managers investing locally present better performance than those preferring foreign markets. It should be noted though that this impact is reverted when fund managers exhibit market timing skills. Koulis et al., (2011) conduct a research on the 
performance of fifteen Greek mutual equity funds trying to detect which equity fund managers have selectivity skills and market timing. The methodology they employ is based on the Treynor-Mazuy model and Sharpe and Treynor measures. They conclude that the examined domestic mutual equity funds' managers have not exhibited selectivity skills and presented minimum market timing ability during the period investigated.

\section{Data and Methodology}

Our analysis is based on weekly data of the quotes of 50 ETFs, rated as one-star ETFs according to the Morningstar's rating scale. Moreover, the S\&P500 index is taken into consideration for the time period spawned between $27 / 10 / 2014$ and 24/09/2018, that is during QE-tapering. Therefore, our analysis is based on 205 observations corresponding to 205 weeks, as well as, a total of 51 variables related to the quotes of the 50 ETFs and the S\&P500 index. The data has been extracted from the Yahoo Finance platform.

We have selected the specific timeframe because it is of great interest as it enables us to look into the manner that global markets acted via the specific modern financial products following the end of QE in the US economy. The latter is of primary importance for the global financial system.

The reason for selecting the particular period of monetary policy, known as QEtapering or taper tantrum is that it represents the period of normalization of monetary action taking by the Federal Reserve that followed times of out of the ordinary liquidity injections. Moreover, the particular global ETFs have been selected as they allow a clearer view of how weak assets in financial markets react when extraordinary measures have been terminated. These ETFs are considered to be of lower rating, according to Morningstar, which has rated them as one-star ETFs. Thereby, extreme cases of highly sophisticated financial assets can be considered through the established framework of CAPM and the Sharpe and Treynor ratios.

Introducing the ETFs of our analysis and the S\&P500 index, we provide the following table 1 that presents the descriptive statistics.

Table 1: Descriptive statistics of the 50 ETFs and of the S\&P500 index ${ }^{1}$

\begin{tabular}{c|c|r|r|r|r|r|r|}
\hline \multicolumn{1}{c}{ Avg } & \multicolumn{1}{l}{ Std. Dev. } & \multicolumn{1}{l}{ Min } & \multicolumn{1}{l}{ Max. } & \multicolumn{1}{l}{ Var. } & \multicolumn{1}{l}{ Asym. } & Kurt. \\
\hline SP500 & 0.0018 & 0.0155 & -0.0615 & 0.0373 & 0.0002 & -1.0022 & 6.0587 \\
\hline BIZD & 0.0010 & 0.0200 & -0.0781 & 0.0604 & 0.0004 & -0.7777 & 5.6190 \\
\hline URE & 0.0015 & 0.0379 & -0.1052 & 0.1022 & 0.0014 & -0.2096 & 2.9734 \\
\hline WBIB & -0.0001 & 0.0167 & -0.0659 & 0.0794 & 0.0003 & -0.0421 & 6.1192 \\
\hline$W B I G$ & 0.0006 & 0.0131 & -0.0413 & 0.0560 & 0.0002 & -0.1033 & 4.6782 \\
\hline DEW & 0.0007 & 0.0180 & -0.0637 & 0.0547 & 0.0003 & -0.5128 & 4.7196 \\
\hline DWX & 0.0000 & 0.0217 & -0.0696 & 0.0734 & 0.0005 & -0.1748 & 4.3338 \\
\hline
\end{tabular}

\footnotetext{
1 The descriptive statistics in table 1 are based on 204 logarithmic differences of the corresponding time series. Comma is the decimal point separator character.
} 


\section{Studies in Business and Economics no. 15(1)/2020}

\begin{tabular}{|c|c|c|c|c|c|c|c|}
\hline$W B I C$ & -0.0002 & 0.0137 & -0.0517 & 0.0520 & 0.0002 & -0.2691 & 4.9125 \\
\hline PLW & 0.0002 & 0.0100 & -0.0416 & 0.0258 & 0.0001 & -0.5612 & 4.2332 \\
\hline WBIL & 0.0008 & 0.0128 & -0.0466 & 0.0622 & 0.0002 & -0.1730 & 6.4391 \\
\hline DVYE & 0.0002 & 0.0264 & -0.0868 & 0.0825 & 0.0007 & -0.1380 & 3.9334 \\
\hline$W B I A$ & -0.0001 & 0.0171 & -0.0675 & 0.0789 & 0.0003 & -0.1360 & 5.5828 \\
\hline$R L Y$ & 0.0000 & 0.0142 & -0.0440 & 0.0483 & 0.0002 & -0.1959 & 3.9399 \\
\hline PLND & -0.0002 & 0.0295 & -0.0863 & 0.0774 & 0.0009 & 0.0113 & 2.8130 \\
\hline WBIE & 0.0008 & 0.0150 & -0.0552 & 0.0532 & 0.0002 & -0.6580 & 5.4919 \\
\hline$D V Y A$ & -0.0002 & 0.0236 & -0.0869 & 0.1023 & 0.0006 & 0.2104 & 5.8767 \\
\hline$F J P$ & 0.0012 & 0.0215 & -0.0883 & 0.0503 & 0.0005 & -0.9092 & 5.4725 \\
\hline SCTO & 0.0006 & 0.0157 & -0.0904 & 0.0867 & 0.0002 & -0.1807 & 11.9740 \\
\hline FTRI & -0.0016 & 0.0369 & -0.1376 & 0.2112 & 0.0014 & 0.2006 & 9.1661 \\
\hline$L T L$ & 0.0004 & 0.0483 & -0.1342 & 0.1386 & 0.0023 & -0.3185 & 3.3645 \\
\hline$F M F$ & 0.0003 & 0.0122 & -0.0446 & 0.0425 & 0.0001 & -0.1696 & 4.5804 \\
\hline$B B R C$ & -0.0005 & 0.0232 & -0.0864 & 0.0665 & 0.0005 & -0.2505 & 4.1981 \\
\hline EUFN & 0.0001 & 0.0279 & -0.1167 & 0.0674 & 0.0008 & -0.3601 & 4.1690 \\
\hline$W B I D$ & 0.0001 & 0.0158 & -0.0532 & 0.0759 & 0.0002 & 0.1452 & 5.6629 \\
\hline URA & -0.0019 & 0.0464 & -0.1080 & 0.1781 & 0.0022 & 0.9667 & 4.7644 \\
\hline$A R G T$ & 0.0012 & 0.0320 & -0.0824 & 0.1041 & 0.0010 & -0.0063 & 3.9109 \\
\hline UYG & 0.0032 & 0.0388 & -0.1451 & 0.1476 & 0.0015 & -0.5019 & 5.3050 \\
\hline$E W I$ & 0.0001 & 0.0286 & -0.1195 & 0.0596 & 0.0008 & -0.5033 & 3.7987 \\
\hline $\mathrm{ClZ}$ & 0.0002 & 0.0161 & -0.0643 & 0.0385 & 0.0003 & -0.8361 & 4.9178 \\
\hline$F R N$ & -0.0002 & 0.0212 & -0.0844 & 0.0601 & 0.0004 & -0.3240 & 4.5103 \\
\hline EMFM & -0.0004 & 0.0245 & -0.0764 & 0.0830 & 0.0006 & 0.0240 & 4.2983 \\
\hline IGN & 0.0023 & 0.0226 & -0.0900 & 0.0735 & 0.0005 & -0.4117 & 4.7294 \\
\hline$F A N$ & 0.0013 & 0.0233 & -0.0839 & 0.0733 & 0.0005 & -0.2057 & 4.4208 \\
\hline GRID & 0.0016 & 0.0241 & -0.0869 & 0.0553 & 0.0006 & -0.4620 & 3.8923 \\
\hline VNM & -0.0007 & 0.0304 & -0.0953 & 0.1191 & 0.0009 & 0.2058 & 4.2583 \\
\hline SSO & 0.0037 & 0.0331 & -0.1249 & 0.0844 & 0.0011 & -0.9924 & 5.6833 \\
\hline SEA & -0.0022 & 0.0313 & -0.1194 & 0.0966 & 0.0010 & -0.3253 & 4.3287 \\
\hline$D D M$ & 0.0044 & 0.0345 & -0.1276 & 0.1058 & 0.0012 & -0.8039 & 5.3807 \\
\hline FTAG & -0.0033 & 0.0329 & -0.1151 & 0.1841 & 0.0011 & 0.0858 & 8.5664 \\
\hline BJK & 0.0000 & 0.0276 & -0.0970 & 0.0727 & 0.0008 & -0.4645 & 3.7289 \\
\hline$P B D$ & 0.0001 & 0.0234 & -0.1003 & 0.0659 & 0.0005 & -0.6250 & 5.0447 \\
\hline HILO & 0.0001 & 0.0245 & -0.0744 & 0.0771 & 0.0006 & -0.1701 & 3.4350 \\
\hline
\end{tabular}




\section{Studies in Business and Economics no. 15(1)/2020}

\begin{tabular}{c|r|r|r|r|r|r|r|}
\hline UYM & 0.0014 & 0.0456 & -0.1751 & 0.1428 & 0.0021 & -0.5804 & 4.4707 \\
\hline SAA & 0.0041 & 0.0409 & -0.1554 & 0.1854 & 0.0017 & 0.2009 & 5.3740 \\
\hline UWM & 0.0034 & 0.0422 & -0.1648 & 0.1890 & 0.0018 & -0.0995 & 5.3952 \\
\hline QCLN & 0.0005 & 0.0287 & -0.0971 & 0.0831 & 0.0008 & -0.6229 & 4.2589 \\
\hline PBW & -0.0006 & 0.0316 & -0.1164 & 0.1110 & 0.0010 & -0.3679 & 5.0464 \\
\hline GEX & 0.0003 & 0.0257 & -0.0956 & 0.0856 & 0.0007 & -0.4804 & 4.4597 \\
\hline TAN & -0.0025 & 0.0447 & -0.1642 & 0.1752 & 0.0020 & -0.3139 & 5.4642 \\
\hline INXX & -0.0005 & 0.0295 & -0.0868 & 0.1039 & 0.0009 & -0.1313 & 3.6045 \\
\hline USD & 0.0061 & 0.0570 & -0.2024 & 0.1170 & 0.0032 & -0.6350 & 3.3751 \\
\hline
\end{tabular}

In summary, the market expressed by the S\&P500 index shows an average return of $0.18 \%$ for the 205 -week period we are considering. The minimum return of the S\&P500 was $-6.15 \%$ while the maximum was $3.73 \%$.

Regarding the ETFs, 17 out of 50 have, in average, negative returns over the QEtapering period which is under scrutiny. Particularly, FTAG and TAN have the lowest average returns $(-0.33 \%$ and $-0.25 \%$ respectively) while URE achieved the highest average return $(0.61 \%)$. Interestingly, the market presented a higher return than the 43 out of the 50 ETFs examined by our study.

The fluctuation of returns of the ETFs under review indicates the volatility of these returns, i.e. the uncertainty and the risk an investor assumes when undertakes an investment. As a result, higher fluctuations lead to higher levels of risk and uncertainty, while the reverse is also true.

It can easily be seen that the most prominent cases are PLWs and FMFs with the lowest fluctuation, thereby also lowest uncertainty and risk but USD and LTL have the highest volatility, on the other hand.

When it comes to estimating the asymmetry of ETFs, the distribution of returns over the prevailing performance is denoted (in number of weeks) by informing the analyst about the likelihood of higher or lower returns than the average performance of each respective ETF. To be more precise, if the asymmetry indicator of an ETF is negative, then negative asymmetry is revealed regarding its returns. This signals to the analyst that the ETF has in most cases achieved lower returns than the average. The opposite holds in cases of positive asymmetry where this indicator is positive. Based on the descriptive statistics presented, 42 out of the 50 ETFs depict a negative asymmetry having achieved lower yields on average for most weeks. The ETF named SSO is the most evident among those having negative asymmetry while URA among those that exhibit positive asymmetry.

In practice, if an investor needs to make a decision based on the historical data of the ETFs under scrutiny, considering their expected returns, she would expect that SSO would pay off high returns as it has achieved a positive expected return. Therefore there is a high probability of achieving higher than expected performance.

Additionally, boxplots of the variables investigated are presented in Graphs 1a, 1b, 1c, 1d, $1 \mathrm{e}, 1 \mathrm{f}$. 
Graph 1a - Boxplot of the first 8 ETFs and of the S\&P500 index

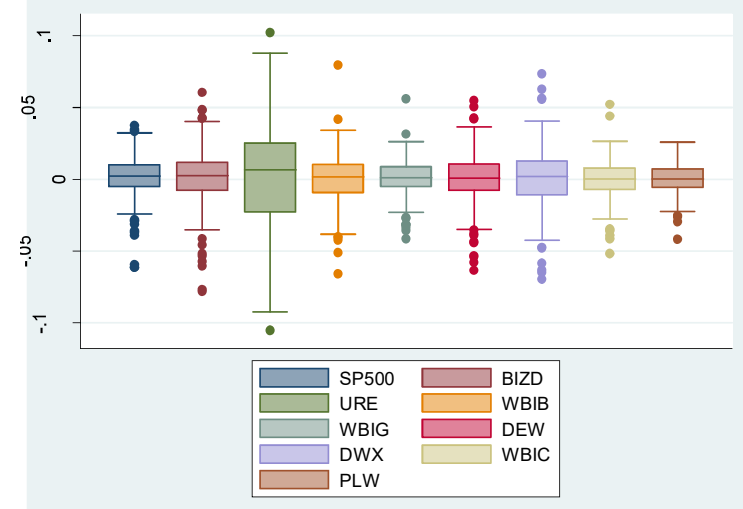

\section{Graph 1b - Boxplot of 9 ETFs}

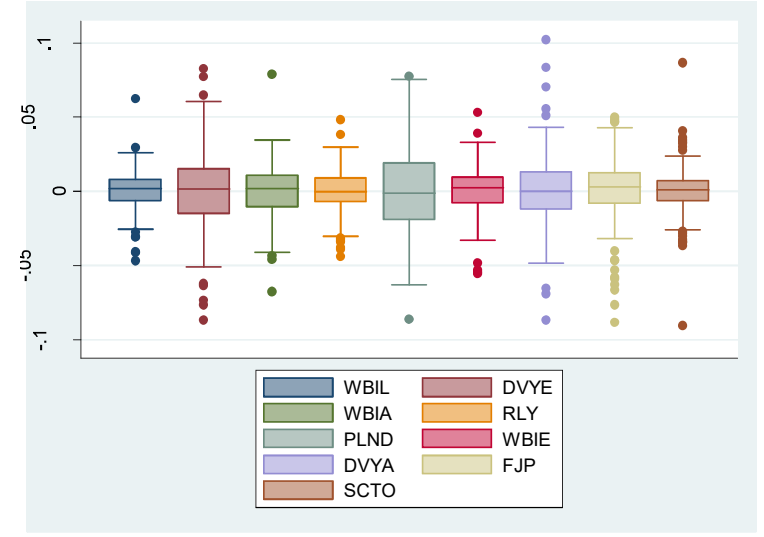

Graph 1c - Boxplot of 9 ETFs

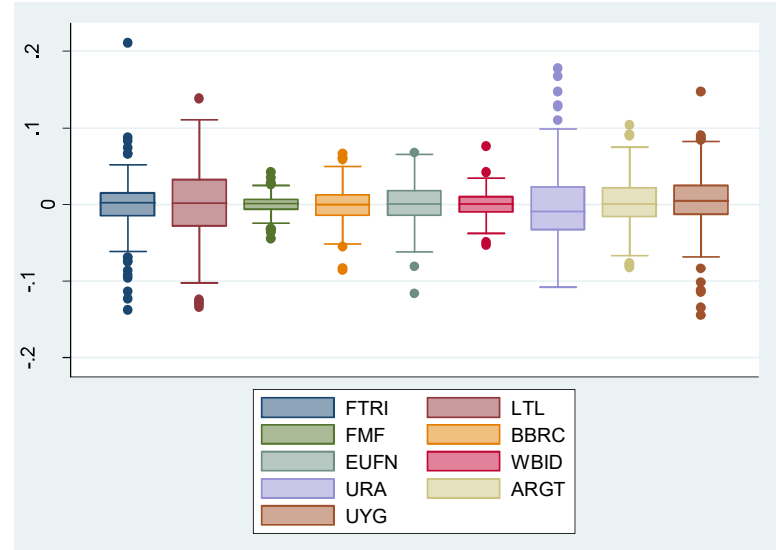




\section{Graph 1d - Boxplot of 9 ETFs}

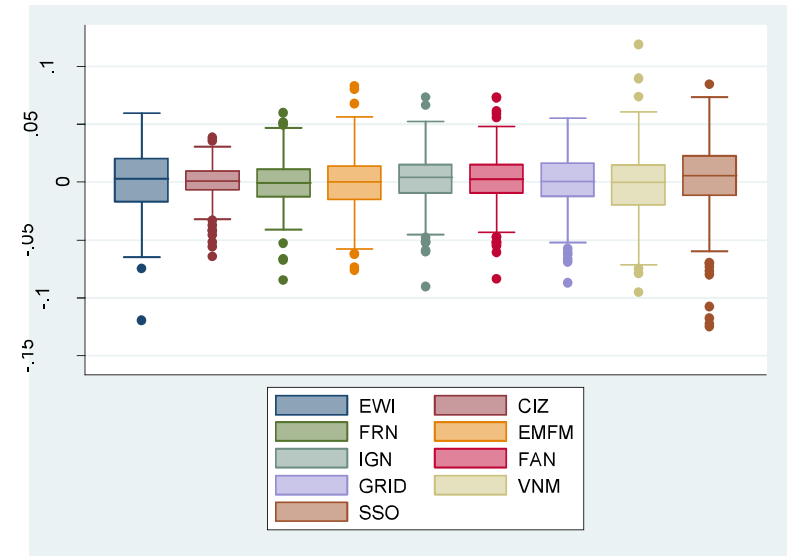

\section{Graph 1e-Boxplot of 9 ETFs}

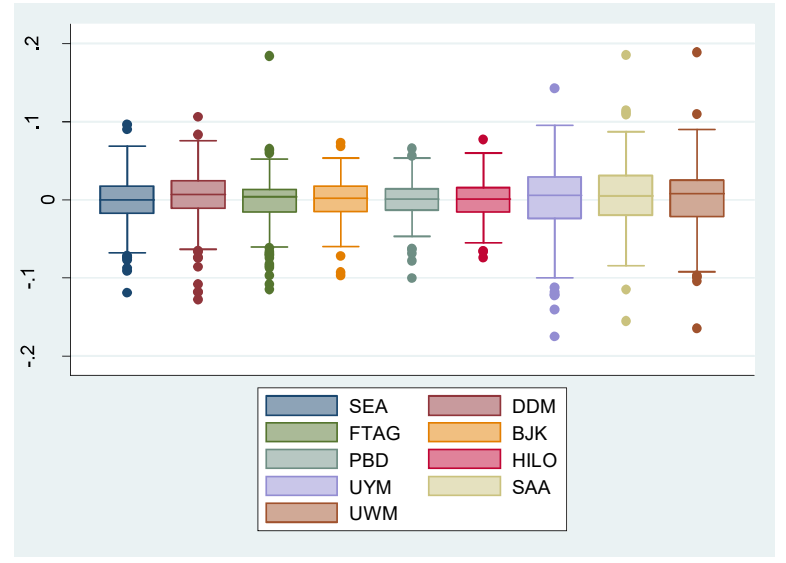

\section{Graph 1f - Boxplot of 9 ETFs}

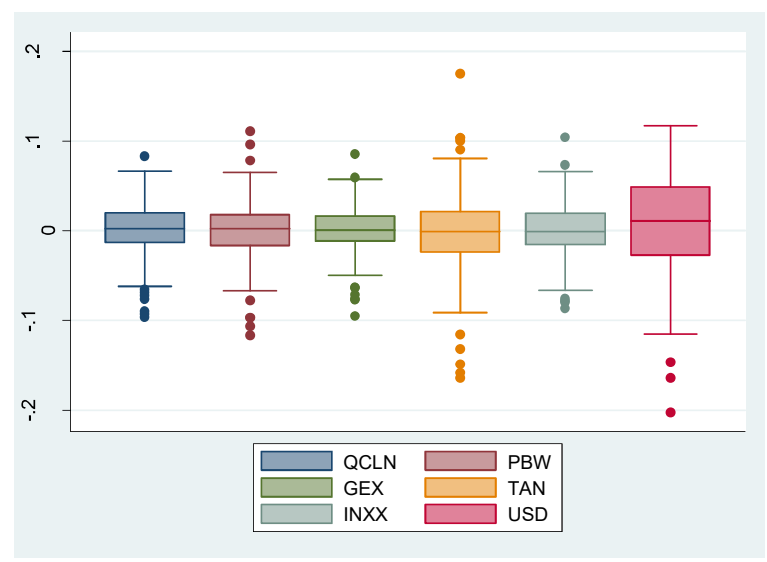

As far as the kurtosis indicator is concerned, it helps the reader to understand how the different performance levels of each ETF are distributed around the average performance, that is, each ETF's expected yield.

A higher kurtosis index indicates that the distribution of the yields of an ETF is subtler, i.e. most of the weekly yields achieved are close to the expected yield over the 
entire timeframe. According to the principles of normal distribution, if the kurtosis index is 3 or higher, we may claim that we have a leptokurtic distribution of yields. On the other hand, we are talking about a platykurtic distribution of yields.

In the case of the ETF examined by our study, 49 out of the 50 ETFs have a leptokurtic distribution of returns with FTRI and SCTO being the prominent cases, where an analyst might consider overwhelmingly higher the probability of yields close to what is expected, when compared to the rest of the ETFs, provided that any other related factor which may affect these ETFs remains constant (ceteris paribus). In the same way, an analyst would expect a low probability of yields near the average, especially for PLND and URE which have the lowest kurtosis indicators among all ETFs covered by our study.

In summary, our findings based on descriptive statistics are confirmed by the boxplot graphs we have provided. The majority of the ETFs investigated present a leptokurtic distribution of returns signaling a higher frequency, expressed in number of weeks, of returns around the median return which is presented by the horizontal line within the shaded square. Thereby, there is a smaller number of ETFs exhibiting low kurtosis. The prominent cases of ETFs with a large range, i.e. a high numerical distance between the maximum and minimum return achieved over the test period, are indicated by the boxplot graphs through the horizontal lines above and below the shaded rectangle.

For our analysis, we mainly rely on the Capital Asset Pricing Model (CAPM), the Sharpe ratio, the Treynor ratio, the $\alpha, \beta$ and the $\alpha / \beta$ ratio extracted from the regression results of the CAPM model.

\subsection{Sharpe ratio}

The Sharpe ratio estimates the expected excess return on an investment asset relative to the risk-free rate of the market adjusted for its overall risk. In a nutshell, it shows its expected excess return for each risk unit and hence enables comparisons between different securities / indices when they have different levels of risk and price volatility.

Basic equation

Sharpe $=\frac{E\left(R_{s}-R_{f}\right)}{\sigma_{s}}$

Where:

- $\quad \mathbf{R}_{\mathbf{s}}$ the yield of an investment asset.

- $\quad \mathbf{R}_{\mathbf{f}}$ the risk-free interest rate of the market.

- $\sigma_{\mathrm{s}}$ the standard deviation of the yields of the investment asset.

Specifically for our analysis, we calculate the Sharpe ratio for each ETF fund in the following way:

Sharpe $_{E T F}=\frac{E\left(R_{E T F}\right)}{\sigma_{F T F}}$

Where:

- $\mathbf{R}_{\mathrm{ETF}}$ the return of the ETF under scrutiny.

- $\quad \mathbf{R}_{\mathbf{f}}=\mathbf{0}$ for comparison purposes between the global ETFs of our analysis which belong to different countries.

- $\sigma_{\mathrm{ETF}}$ the standard deviation of the returns of the ETF under investigation. 
Regarding our analysis, the returns $R_{E T F}$ kal RSP500 used for the calculation of the Sharpe ratio follow this formula:

$R_{t}=\frac{Q_{t}-Q_{t-1}}{Q_{t-1}}$

Where:

- $\mathbf{Q}_{t}$ the quote of period $t$ for which the return is calculated.

- $\mathbf{Q}_{\mathrm{t}-1}$ the quote of the previous period.

\subsection{Treynor ratio}

The Treynor ratio assesses the expected excess return on an investment asset in relation to the risk-free interest rate in relation to the benchmark market index. Somewhat similarly to Sharpe ratio, it reveals an asset's expected excess return for each market risk unit, enabling comparisons between different investment assets.

General equation:

Treynor $=\frac{E\left(R_{s}-R_{f}\right)}{\beta}$

Where:

- $\quad \mathbf{R}_{\mathbf{s}}$ the yield of an investment asset.

- $\quad \mathbf{R}_{\mathbf{f}}$ the risk-free interest rate of the market.

- $\quad \boldsymbol{\beta}$ as extracted from the regression results of the CAPM equation.

In this paper, we calculate the Treynor ratio for each ETF as follows:

Treynor $_{\text {ETF }}=\frac{E\left(R_{E T F}\right)}{\beta_{F T F}}$

\subsection{Capital Asset Pricing Model (CAPM)}

The CAPM is an established model of forecasting the returns of investment assets relatively to the benchmark market. CAPM is prestigious in the field of finance and banking, allowing an analyst (Fama and French, 2004) to calculate Jensen's Alpha and Beta coefficients. It therefore helps an analyst to evaluate the ability of an asset to achieve profit irrespective of market conditions, but also judge on the level of the return relatively to the market and the systematic risk that exists due to the latter (Hodges et al., 2003).

Basic model equation:

$$
\left(R_{s}-R_{f}\right)=\alpha+\beta\left(R_{m}-R_{f}\right)
$$

Where:

- $\quad \mathbf{R}_{\mathbf{s}}$ the return of an investment asset.

- $\quad \mathbf{R}_{\mathbf{m}}$ the return of the benchmark market which the investment asset is compared to.

- $\quad \mathbf{R}_{\mathbf{f}}$ the risk-free interest rate of the economy

More specifically:

- $\mathbf{R}_{\mathrm{ETF}}$ is the return of the ETF calculated as a logarithmic difference of the ETF initial quotes.

- $\mathbf{R}_{\mathbf{S P 5 0}}$ is the return of the benchmark S\&P500 index as a logarithmic difference between its initial quotes which we compare each fund to. 
- $\quad \mathbf{R}_{\mathbf{f}}=\mathbf{0}$ for comparison purposes between the global ETFs which belong to different countries.

- $\quad \boldsymbol{\alpha}$ is Jensen's Alpha, which shows the selectivity skills of the ETF's fund manager, i.e. the fund manager's capability to achieve profits or no. To be more precise:

$\circ$ if $\alpha<0$, then the fund manager of the ETF has poor selectivity skills since it generates losses irrespective of market conditions. A smaller value indicates a greater lack of selectivity skills for the manager.

$\circ$ if $\mathbf{\alpha}=\mathbf{0}$, then the manager does not possess selectivity skills and does not achieve profits or generate losses regarding the ETF fund regardless of market conditions.

$\circ$ if $\boldsymbol{\alpha}>\mathbf{0}$, then the manager exhibits selectivity skills by achieving profits for the ETF regardless of market conditions. A higher value indicates a higher level of selectivity skills for the manager.

- $\quad \boldsymbol{\beta}$ is the Beta coefficient that indicates whether the ETF is characterized as bullish, neutral or bearish in terms of the market. Specifically:

$\circ \quad$ if $\boldsymbol{\beta}<\mathbf{0}$, then the ETF has behavior opposite to that of the market, thereby is unable to achieve positive returns in normal times

- If $0<\beta<1$, then the ETF has "bearish" behavior resulting in a lower return and systematic risk in relation to the market.

$\circ$ if $\beta=1$, then the ETF follows the market by achieving the same returns and the same level of risk as the market.

$\circ$ if $\beta>1$, then the ETF has "bullish" behavior resulting in a higher return and systematic risk level in relation to the market.

Ratio a / $\beta$

We calculate the $\alpha / \beta$ ratio for each ETF where $\alpha$ and $\beta$ are extracted from the regression results when applying CAPM to each respective ETF. The ratio allows us to compare ETF managers' selectivity skills when adapted to indicators of aggressive or not behavior and the systematic risk of the market.

\subsection{Econometric procedure}

For the application of the Capital Asset Pricing Model (CAPM), we have calculated the first logarithmic differences of the initial values of the time series of our variables in order to extract their returns by avoiding the problem of autocorrelation that occurs when using the initial values of our variables. In addition, we applied heteroscedasticity tests in all cases trying to avoid the problem with the Newey - West regression method. Finally, our econometric analysis was based on a statistical significance level of $5 \%$.

\section{Econometric results}

The following Table 2 presents the analysis results of the 50 ETF's based on the methodology that described in a previous paragraph. 


\section{Studies in Business and Economics no. 15(1)/2020}

Table 2: Econometric results ${ }^{1}$ and assessments

\begin{tabular}{|c|c|c|c|c|c|}
\hline ETF & Sharpe & $a$ & $\beta$ & $\alpha / \beta$ & Treynor \\
\hline$B I Z D$ & 0.0598 & $-0.0002(0.846)$ & $0.6847(0.000)^{* * *}$ & -0.0004 & 0.0017 \\
\hline URE & 0.0595 & $-0.0005(0.848)$ & $1.1024(0.000)^{\star * *}$ & -0.0004 & 0.0020 \\
\hline WBIB & 0.0036 & $-0.0016(0.028)^{* *}$ & $0.8376(0.000)^{* \star *}$ & -0.0019 & 0.0001 \\
\hline$W B I G$ & 0.0560 & $-0.0005(0.367)$ & $0.6544(0.000)^{* * *}$ & -0.0008 & 0.0011 \\
\hline$D E W$ & 0.0475 & $-0.0009(0.243)$ & $0.9021(0.000)^{* * *}$ & -0.0010 & 0.0009 \\
\hline$D W X$ & 0.0100 & $-0.0016(0.179)$ & $0.8820(0.000)^{\star * *}$ & -0.0018 & 0.0002 \\
\hline$W B I C$ & -0.0084 & $-0.0014(0.038)^{* *}$ & $0.6483(0.000)^{* \star *}$ & -0.0021 & -0.0002 \\
\hline$P L W$ & 0.0302 & $0.0006(0.396)$ & $-0.1763(0.001)^{* * *}$ & -0.0032 & -0.0017 \\
\hline WBIL & 0.0672 & $-0.0004(0.535)$ & $0.6262(0.000)^{* * *}$ & -0.0006 & 0.0014 \\
\hline DVYE & 0.0190 & $-0.0016(0.295)$ & $0.9775(0.000)^{\star * *}$ & -0.0016 & 0.0005 \\
\hline$W B I A$ & 0.0024 & $-0.0017(0.0298) * *$ & $0.8620(0.000)^{* * *}$ & -0.0019 & 0.0000 \\
\hline$R L Y$ & 0.0073 & $-0.0010(0.198)$ & $0.5658(0.000)^{* * *}$ & -0.0018 & 0.0002 \\
\hline PLND & 0.0094 & $-0.0014(0.46)$ & $0.7096(0.000)^{* * *}$ & -0.0020 & 0.0004 \\
\hline WBIE & 0.0595 & $-0.0007(0.259)$ & $0.8036(0.000)^{\star * *}$ & -0.0008 & 0.0011 \\
\hline DVYA & 0.0022 & $-0.0018(0.187)$ & $0.8660(0.000)^{\star \star *}$ & -0.0021 & 0.0001 \\
\hline FJP & 0.0671 & $-0.0002(0.874)$ & $0.7789(0.000)^{* \star *}$ & -0.0003 & 0.0018 \\
\hline SCTO & 0.0482 & $-0.0003(0.739)$ & $0.5312(0.000)^{\star * *}$ & -0.0006 & 0.0014 \\
\hline FTRI & -0.0252 & $-0.0040(0.075)^{*}$ & $1.3041(0.000)^{\star * *}$ & -0.0030 & -0.0007 \\
\hline$L T L$ & 0.0327 & $-0.0022(0.47)$ & $1.4529(0.000)^{\star * *}$ & -0.0015 & 0.0011 \\
\hline$F M F$ & 0.0282 & $0.0002(0.828)$ & $0.0455(0.413)^{\star \star *}$ & 0.0041 & 0.0076 \\
\hline$B B R C$ & -0.0116 & $-0.0020(0.146)$ & $0.8171(0.000)^{* * *}$ & -0.0025 & -0.0003 \\
\hline EUFN & 0.0170 & $-0.0017(0.287)$ & $1.0052(0.000)^{* \star *}$ & -0.0017 & 0.0005 \\
\hline$W B I D$ & 0.0118 & $-0.0013(0.056)$ * & $0.7801(0.000)^{* \star *}$ & -0.0017 & 0.0002 \\
\hline URA & -0.0178 & $-0.0040(0.176)$ & $1.1435(0.000)^{\star \star *}$ & -0.0035 & -0.0007 \\
\hline$A R G T$ & 0.0548 & $-0.0008(0.682)$ & $1.1223(0.000)^{* * *}$ & -0.0007 & 0.0016 \\
\hline UYG & 0.10240 & $-0.00042(0.796)$ & $2.01503(0.000) * * *$ & -0.00020 & 0.00196 \\
\hline$E W I$ & 0.01713 & $-0.01457(0.416)$ & $0.85477(0.000)^{* * *}$ & -0.01704 & 0.00056 \\
\hline $\mathrm{ClZ}$ & 0.02029 & $-0.00106(0.207)$ & $0.70108(0.000)^{* * *}$ & -0.00152 & 0.00046 \\
\hline$F R N$ & 0.00070 & $-0.00154(0.22)$ & $0.74258(0.000)^{* \star *}$ & -0.00208 & 0.00002 \\
\hline EMFM & -0.00299 & $-0.00189(0.197)$ & $0.84473(0.000)^{* * *}$ & -0.00224 & -0.00008 \\
\hline
\end{tabular}

1 p-values appears inside parenthesis. The ${ }^{\alpha \text { 's ka } \beta^{\prime} \text { s without asterisk }}$ are statistical no significant and further analysis must be obtained before any other action. The a's kal $\beta^{\prime}$ s with one, two or three asterisks, are statistical significant with significant levels of ${ }^{1} 0 \%, 5 \%$ and $1 \%$ accordingly.

$-206-$




\section{Studies in Business and Economics no. 15(1)/2020}

\begin{tabular}{c|c|c|c|c|r|}
\hline IGN & 0.11399 & $0.00042(0.7)$ & $1.04532(0.000)^{* * *}$ & 0.00040 & 0.00245 \\
\hline$F A N$ & 0.06795 & $0.00000(0.999)$ & $0.72748(0.000)^{* * *}$ & 0.00003 & 0.00217 \\
\hline GRID & 0.07780 & $-0.00027(0.833)$ & $1.02846(0.000)^{* * *}$ & -0.00026 & 0.00182 \\
\hline VNM & -0.00731 & $-0.00208(0.293)$ & $0.77657(0.000)^{* * *}$ & -0.00268 & -0.00028 \\
\hline SSO & 0.12950 & $0.00019(0.843)$ & $1.94327(0.000)^{* * *}$ & 0.00009 & 0.00218 \\
\hline SEA & -0.05469 & $-0.00449(0.009)^{* * *}$ & $1.28365(0.000)^{* * *}$ & -0.00350 & -0.00132 \\
\hline DDM & 0.14490 & $0.00082(0.475)$ & $1.96229(0.000)^{* * *}$ & 0.00042 & 0.00252 \\
\hline FTAG & -0.08458 & $-0.00533(0.008)^{* * *}$ & $1.11201(0.000)^{* * *}$ & -0.00479 & -0.00250 \\
\hline$B J K$ & 0.01486 & $-0.00170(0.299)$ & $0.96335(0.000)^{* * *}$ & -0.00176 & 0.00042 \\
\hline$P B D$ & 0.01393 & $-0.00172(0.17)$ & $0.98598(0.000)^{* * *}$ & -0.00174 & 0.00032 \\
\hline$H I L O$ & 0.01643 & $-0.00153(0.279)$ & $0.91205(0.000)^{* * *}$ & -0.00168 & 0.00044 \\
\hline UYM & 0.05395 & $-0.00253(0.241)$ & $2.18784(0.000)^{* * *}$ & -0.00115 & 0.00111 \\
\hline$S A A$ & 0.12040 & $0.00083(0.69)$ & $1.83328(0.000)^{* * *}$ & 0.00045 & 0.00271 \\
\hline UWM & 0.10056 & $-0.00059(0.735)$ & $2.20176(0.000)^{* * *}$ & -0.00027 & 0.00193 \\
\hline QCLN & 0.03264 & $-0.00177(0.23)$ & $1.274620 .000)^{* * *}$ & -0.00139 & 0.00072 \\
\hline$P B W$ & -0.00229 & $-0.00287(0.1) *$ & $1.28030(0.000)^{* * *}$ & -0.00224 & -0.00005 \\
\hline$G E X$ & 0.02540 & $-0.00158(0.258)$ & $1.05852(0.000)^{* * *}$ & -0.00149 & 0.00061 \\
\hline$T A N$ & -0.03447 & $-0.00499(0.074)^{* *}$ & $1.37151(0.000)^{* * *}$ & -0.00363 & -0.00111 \\
\hline INXX & -0.00283 & $-0.00187(0.329)$ & $0.75451(0.000)^{* * *}$ & -0.00248 & -0.00011 \\
\hline USD & 0.13618 & $0.00136(0.631)$ & $2.60747(0.000)^{* * *}$ & 0.00052 & 0.00294 \\
\hline
\end{tabular}

According to our analysis, 11 out of 50 ETFs (WBIC, FTRI, BBRC, URA, EMFM, VNM, SEA, FTAG, PBW, TAN, INXX) have negative Sharpe ratios and are characterized on average by negative returns adjusted for their overall risk. The rest of the ETFs have positive Sharpe ratios and are therefore characterized by positive, on average, overall riskadjusted returns.

FTAG, has the lowest Sharpe ratio of $-8,458 \%$, with a negative risk-adjusted expected return. On the other hand, DDM presents the highest Sharpe ratio of $14,49 \%$, achieving the highest (among all ETFs) expected return adjusted to its overall risk, followed by USD (13,61\%), SSO (12,95\%), SAA $(12,04 \%)$ and the IGN $(11,39 \%)$.

With respect to the Treynor ratio of our analysis, ETF funds WBIC, PLW, FTRI, BBRC, URA, EMFM, VNM, SEA, FTAG, PBW, TAN, INXX have a negative Treynor ratio, while the remaining 38 have positive with the highest one being the SSA. Consequently, the 12 ETFs with a negative Treynor ratio failed in the meanwhile to deliver a positive return during the QE-tapering, but SAA has managed to yield the maximum average return adjusted to the systematic market risk at the same time.

By comparing the Treynor and Sharpe ratios, we could observe that although they are quite similar in their mentality, Treynor ratio denotes the expected return of each ETF on which it is applied, adjusted for the systematic market risk expressed by the S\&P500 
index, instead of its overall risk due to volatility, which Sharpe considers. Both ratios are negative for the ETF funds WBIC, FTRI, BBRC, URA, EMFM, VNM, SEA, FTAG, PBW, TAN, INXX due to their negative expected returns. Furthermore, for the 11 specific ETFs, Sharpe ratio appears more times as negative when compared to Treynor ratio values, suggesting that the overall risk posed by these ETFs is less than the systematic market risk. On the contrary, the rest of the ETFs of our analysis reveal a higher Sharpe ratio than the Treynor ratio, which gives them a better risk-return nexus.

Considering the Treynor and Sharpe ratios, investors mainly deciding based on asset performance and risk factors, would have no reason to choose those 11 specific ETFs having negative Sharpe and Treynor ratios, not only because of their negative expected returns but also because they are not sufficiently risk-adjusted ETF's, compared to alternatives they may prefer.

Taking into account Jensen's Alpha of every regression from the application of the Capital Asset Pricing Model (CAPM), only 8 of the 50 ETFs investigated show nonnegative values. PLWs, FMFs, IGNs, FANs, SSOs, DDMs, SAAs, USD reveal the pure selectivity skills of their managers since Jensen's alpha, although of positive sign, is marginally above zero. This could be translated as their managers achieving to generate profits for investors, irrespective of market conditions. On the other hand, the managers of the remaining 42 ETFs show lack of selectivity skills. FTAG, TAN and SEA present the weakest management capacity among the 50 ETFs concerned. As a result, the managers of those 42 ETFs, in the absence of management capabilities (selectivity skills), are less likely to bring about profits to their investors.

When it comes to results about Jensen's Alpha, it is revealed that an investor may feel safer when investing in PLW, FMF, IGN, FAN, SSO, DDM, SAA, USD, regardless of the market's conditions. In contrast, in the case of the remaining $42 \mathrm{ETFs}$, investors should be particularly cautious, since they can only rely on achieving high returns by each ETF only by being based on aggressive behavior in relation to the market.

Regarding the calculated Beta coefficient of each regression, PLW ETF follows an opposite direction in relation to market, thereby is characterized by a negative sign. The remaining 49 ETFs of our analysis follow a directional relationship to market conditions to a greater or lesser extent. 28 ETFs present a "bearish" behavior in terms of returns, achieving lower than the average market's returns, but with less exposal to systematic risk. In contrast, 21 of the 50 ETFs we are dealing with, appear to be "bullish", yielding higher than the market, returns but also exposing the investors to a greater systematic risk. The most bearish ETF is the FMF, while the most bullish is the USD.

Overall, with respect to Betas, investors have different levels of risk-loving when selecting among the ETFs, weighing in their portfolio the systematic market risk to achieve different levels of return. For example, if investors seek higher returns without being considered whether risk increases or not (risk lovers), they should prefer some ETF among USD, UYG, UWM, UYM, DDM, SSO that show bullish behavior. On the other hand, if investors do not mind lower levels of return combined with lesser risk (risk averse attitude), they should select any of the 28 ETFs that exhibit bearish behavior. In addition, if investors seek a moderate level of risk and yield, they should select an ETF with a Beta factor close to 1 such as PBD, BJK, DVYE and EUFN. 
Moreover, we have calculated the $\alpha$ / $\beta$ ratio based on the extracted $\alpha$ and $\beta$ from the regression concerning each ETF. SSO, IGN, FAN, DDM, USD, SAA and FMF present a positive $\alpha$ / $\beta$ ratio that reveals positive but not intense selectivity skills by their managers when adjusted to their respective systematic risk expressed by $\beta$ (Beta). On the other hand, all other ETFs have a negative $\alpha$ / $\beta$ ratio indicating lack of selectivity skills by the respective managers per market's systematic risk unit. If investors are interested in choosing ETFs to invest their capital, by considering each manager's selectivity skills and the aggressiveness based on which an ETF achieves its return in relation to the market, they may consult the $\alpha / \beta$ ratio by selecting ETFs with higher ratios. However, as far as the ETFs of our study are concerned, investors have no obvious profitable options since most alternatives have a negative $\alpha / \beta$ ratio. Exceptions include FMF, IGN, FAN, SSO, DDM and USD with a positive $\alpha / \beta$ ratio.

\section{Conclusions}

In the present study, we investigated 50 global low-rated ETFs (ranked with one star on the Morningstar scale) by employing the well-established CAPM model. We adopted 205 observations of weekly data for a period of about four years between 2014 and 2018, representing US QE-tapering. In order to have a representative market index, we selected the S\&P500 as the benchmark index.

This paper has undertaken this research in order to cast light into the selectivity skills and the level of aggressiveness in the behavior of mutual fund managers concerning global low-rated ETFs during the normalization of monetary policy in the US. The latter means that interest rates have escaped from the Zero Lower Bound (ZLB). The measures we have employed are the Sharpe and Treynor ratios, the Jensen's Alpha, the Betas and the $a / b$, based on the CAPM.

Our analysis reveals that most of these low-rated ETFs had positive returns on average over the period under scrutiny, but only seven of them managed to outperform the market. 39 out of 50 ETFs had a positive Sharpe ratio, while 38 out of 50 had a positive Treynor ratio. By investing in the specific 39 ETFs with a positive Sharpe ratio, investors could expect positive returns on any given level of total risk. Similarly, in the case of the 38 ETF funds with positive Treynor ratios, the investors having selected them could expect to be able to earn a higher return on any given level of systematic risk, or in other words per unit of systematic risk.

In addition, the ETFs we tested, in 42 cases did not reveal selectivity skills by their respective managers. Thereby, during periods of normalization of monetary policy ETF managers are not deemed to be capable of outperforming the market. Remarkably, 21 out of the 50 ETFs exhibit bullish behavior, 28 are revealed to have bearish behavior, and one ETF follows a direction opposite to the market.

The aim of this study is to provide a roadmap for further academic research in this field of economics that is not yet adequately explored. One of the main motivations of the authors has been to cast light on a less known subject and help interested readers to better explore unchartered scientific waters. To the best of our knowledge, this is the first 
study that undertakes investigation about financial performance of global low-rated ETFs after the end of QE. Findings from this study should be useful for investors as well as policy makers as it enlightens concerning performance of highly sophisticated financial instruments during exiting the period of extra-easing policies in an economy of major importance.

\section{References}

Aizenman, J., Binici, M., \& Hutchison, M. M. (2014). The transmission of Federal Reserve tapering news to emerging financial markets (No. w19980). National Bureau of Economic Research.

Chari, A., Stedman, K. D., \& Lundblad, C. (2017). Taper tantrums: Qe, its aftermath and emerging market capital flows (No. w23474). National Bureau of Economic Research.

Fama, E. F. (2004). The Capital Asset Pricing Model: Theory and Evidence. Journal of Economic Perspectives, 25-46.

Fawley, B. W., \& Neely, C. J. (2013). Four stories of quantitative easing. Federal Reserve Bank of St. Louis Review, 95(1), 51-88.

Foley-Fisher, N., Ramcharan, R., \& Yu, E. (2016). The impact of unconventional monetary policy on firm financing constraints: Evidence from the maturity extension program. Journal of Financial Economics, 122(2), 409-429.

Gregoriou, G. N., \& Gueyie, J. P. (2003). Risk-adjusted performance of funds of hedge funds using a modified Sharpe ratio. The Journal of wealth management, 6(3), 77-83.

Hodges, C. T. (2003). Beta, the Treynor ratio, and long-run investment horizons. Applied Financial Economics, 503-508.

Israelsen, C. L. (2005). A refinement to the Sharpe ratio and information ratio. Journal of Asset Management, 5(6), 423-427.

Jensen, M. C. (1968). The performance of mutual funds in the period 1945-1964. The Journal of finance, 23(2), 389-416.

Jobson, J. D., \& Korkie, B. M. (1981). Performance hypothesis testing with the Sharpe and Treynor measures. The Journal of Finance, 36(4), 889-908.

Joyce, M., Miles, D., Scott, A., \& Vayanos, D. (2012). Quantitative easing and unconventional monetary policy-an introduction. The Economic Journal, 122(564), F271-F288.

Kostovetsky, L. (2003). Index mutual funds and exchange-traded funds. Journal of Portfolio Management, 29(4), 80-92.

Koulis, A., Beneki, C., Adam, M., \& Botsaris, C. (2011). An Assessment of the Performance of Greek Mutual Equity Funds Selectivity and Market Timing. Applied Mathematical Sciences, 5(4), 159-171.

Mansor, F., \& Bhatti, M. I. (2011). Risk and return analysis on performance of the Islamic mutual funds: evidence from Malaysia. Global Economy and Finance Journal, 4(1), 19-31.

Markowitz, H. (1952). Portfolio Selection. The Journal of Finance, 77-91.

Meinusch, A., \& Tillmann, P. (2015, 09). Quantitative easing and tapering uncertainty: Evidence from Twitter. Marburg: Faculty of Business Administration and Economics, University of Marburg.

Papadamou, S., Siriopoulos, C. (2004). American Equity Mutual Funds in European Markets: Hot Hands Phenomenon and Style Analysis. International Journal of Finance and Economics, 9:85-97. DOI:10.1002/ijfe.233

Pilotte, E. S. (2006). Sharpe and Treynor Ratios on Treasury Bonds. The Journal of Business, 149180. 


\section{Studies in Business and Economics no. 15(1)/2020}

Poterba, J. S. (2002). Exchange-Traded Funds: A New Investment Option for Taxable Investors. American Economic Review, 422-427.

Romacho, J. C., \& Cortez, M. C. (2006). Timing and selectivity in Portuguese mutual fund performance. Research in International Business and Finance, 20(3), 348-368.

Scholz, H. (2007). Refinements to the Sharpe ratio: Comparing alternatives for bear markets. Journal of Asset Management, 347-357.

Sharpe, W. (1964). Capital Asset Prices: A Theory of Market Equilibrium Under Conditions of Risk. Journal of Finance, 425-442.

Sharpe, W. (1966). Mutual Fund Performance. Journal of Business, 119-138.

Sharpe, W. F. (1994). The sharpe ratio. Journal of portfolio management, 21(1), 49-58.

Swinkels, L., \& Rzezniczak, P. (2009). Performance evaluation of Polish mutual fund managers. International Journal of Emerging Markets, 4(1), 26-42.

Thanou, E. (2008). Mutual Fund Evaluation During Up and Down Market Conditions: The Case of Greek Equity Mutual Funds, International Research Journal of Finance and Economics, ISSN 1450-2887, issue 13, 84-93.

Treynor, J., \& Mazuy, K. (1966). Can Mutual Funds Outguess the Market? Harvard Business Review, 131-136. 